\title{
Comparing the monetary value of a quality-adjusted life year from the payment card and the open-ended format
}

\author{
Ziping Ye, Fuyao Liu, Jia Ma, Ziyang Zhou, Chen Wang and Lihua Sun*
}

\begin{abstract}
Background: The payment card (PC) format and the open-ended (OE) format are common methods in eliciting willingness-to-pay (WTP) of one additional quality-adjusted life year (QALY). The aim of this research is to compare these two formats in eliciting the monetary value of a QALY.
\end{abstract}

Methods: A contingent valuation survey was carried out using a pre-designed questionnaire with various hypothetical scenarios. The difference between the PC and the OE formats was evaluated by a two-sample equality test. Furthermore, generalized linear models were carried out to control observed heterogeneity and to test theoretical validity.

Results: In total, 461 individuals were involved, among whom 235 (51\%) answered the PC question, while 226 (49\%) answered the OE question. Excluding zero response, the mean WTP values of these two formats for different scenarios varied dramatically, which was from 13,278 to 280,177 RMB for the PC, 18,119 to 620,913 RMB for the OE. The OE format tended to elicit lower values for less serious condition and higher values for more serious condition. However, equality test of mean and median demonstrated insignificant difference of these two formats for all scenarios. For both OE and PC format, most variables were found to have significant effect on the value of WTP/QALY. Moreover, joint estimation indicated a statistically significant positive effect on the OE results. Further analysis demonstrated that the imbalanced zero response distribution caused the main difference of these two formats.

Conclusions: This research indicated insignificantly different WTP/QALY estimates of the PC format and OE format with the grouped data whereas significantly higher estimates of the OE format from the pooled data. These two formats were found to be valid. More research about the difference and the validity of various WTP eliciting methods would be recommended for a robust estimation of WTP/QALY.

Keywords: Willingness-to-pay, Contingent valuation, Payment card, Open-ended question, Threshold

\section{Background}

Budget allocation is one of the most prominent matters for decision makers in health-care systems today. The allocation is a complex, multifaceted issue. One of the vital questions, related to the budget allocation, is how much health-care systems should spend on the

*Correspondence: sunlh@syphu.edu.cn

College of business administration, Shenyang Pharmaceutical University, Shenyang 110016, China improvement of health-related outcome in terms of one additional quality-adjusted life year (QALY). Common decision rules of economic evaluations indicate that an intervention is believed to be cost-effective if the incremental cost-effectiveness ratio (ICER) of costeffectiveness analysis (CEA) falls below the cost-effectiveness threshold value. Generally, there are two main approaches to this value, each taking a perspective from the demand side or supply side of the market $[1,2]$. Those supply-side thresholds represent the health opportunity original author(s) and the source, provide a link to the Creative Commons licence, and indicate if changes were made. The images or other third party material in this article are included in the article's Creative Commons licence, unless indicated otherwise in a credit line to the material. If material is not included in the article's Creative Commons licence and your intended use is not permitted by statutory regulation or exceeds the permitted use, you will need to obtain permission directly from the copyright holder. To view a copy of this licence, visit http://creativecommons.org/licenses/by/4.0/. The Creative Commons Public Domain Dedication waiver (http://creativeco mmons.org/publicdomain/zero/1.0/) applies to the data made available in this article, unless otherwise stated in a credit line to the data. 
cost, indicating that whether a medicine is worthy of its cost depends on whether the amount of health-related outcomes it produces is larger than the health outcomes that could have been generated if some other medicine got funded [3]. Nevertheless, demand-side methods are in line with the method taken in other public sectors as well as a welfarist approach, where the monetary value of one additional QALY is estimated as willingness-to-pay per QALY (WTP/Q) by contingent valuation (CV) surveys. It is believed that WTP/Q can help improve efficiency in the margin within the healthcare sector as well as between sectors [4].

$\mathrm{CV}$ is usually used to elicit monetary values of a nonmarket good or service [5] by requesting participants to state their willingness-to-pay (WTP) for obtaining a good, in this context, for QALY (always a small amount). In the last decade, there are numerous studies estimating WTP/Q [6-13]. Typically, individuals have been asked about their WTP for health gains for which utility values were measured by EQ-5D population tariffs, Time-TradeOff, Standard Gamble or Visual Analogue Scale.

However, great disparities exist in the type of health gain, respondents' characteristics, and survey methodology-all of which may influence the perceived estimates of WTP/Q. Ryen et al. [14] included 24 studies and indicated that the WTP/Q value is significantly higher if the QALY gain comes from life extension rather than quality of life improvements. By comparing 2 similar surveys, Bobinac and colleagues [8] stated that WTP/Q is higher when the health gain in the survey scenario is uncertain. However, the impact of different CV questionnaire format has been barely investigated.

$\mathrm{CV}$ questionnaire format denotes the approach by which the respondent is required to provide their WTP, of which four classical techniques have been in use: iterative bidding, dichotomous choice, open-ended (OE) and payment card (PC) [15]. In this research, we focus on the latter two techniques, the $\mathrm{OE}$ and the $\mathrm{PC}$ format.

The PC technique was proposed by Mitchell [16] and first used in the general economics literature by JonesLee et al. [17]. Respondents were given a specific range of monetary values and asked to select the maximum value they would be willing to pay for a particular benefit. On account of the good performance of imitating real life by letting respondents ponder their WTP, the PC has become a prevalent method of eliciting WTP in health economics. The OE elicitation technique directly asks the respondent the maximum they would be willing to pay in a hypothetical scenario. As respondents are prone to anchoring on proposed values when the elicitation technique suggests the values, the OE method can lead to a more precise and independent WTP value than other elicitation techniques, as it does not suggest an answer
[18]. It was further verified that the $\mathrm{OE}$ format is an effective technique if the final decision depends on a quantile instead of the mean [19].

There are several reasons why the $\mathrm{PC}$ and the $\mathrm{OE}$ method are chosen for this research. First of all, these two methods have been used broadly in estimating WTP per QALY [7-10]. Moreover, the advantages of using the PC and the OE method were that they were easier to understand and they required a short time for interviews, which is really important considering the respondent burden is a major concern due to the complexity of hypothetical scenario in estimating WTP/Q.

Given the popularity of the PC and the $\mathrm{OE}$ in health economics, more specifically, in estimating the monetary value of QALY, a plausible development is a direct comparison of these two formats. Although there is no research comparing these two methods in estimating WTP/QALY, studies have examined the discrepancies of eliciting methods in other fields. A general finding is that for health-related goods, the OE format causes lower WTP values [20, 21]. However, for environmental goods [22] or an ambulance helicopter service [23], relatively equal values were reported.

The aim of this research is straightforward, taking focus on the comparison of the PC and the OE formats. First, we examined the difference of WTP/QALY estimates from these two methods. Furthermore, we investigated the theoretical validity of each method to determine which method elicits more valid monetary value of QALY.

\section{Methods}

\section{Study design and sample}

We conducted a CV survey on general Chinese population between June 1st, 2019 and August 10th, 2019. A relatively low response rate was observed in the pilot study of the probability sample survey. Hence, quota sampling was used in the final survey with quotas based on sex, age, and income. First, study participants were recruited in-person by trained interviewers, then we interviewed those who satisfied the quotas. A questionnaire that measures maximum WTP per QALY for various hypothetical scenarios was used in this research. This survey was carried out with trained interviewers through telephone (a mobile app "WeChat"). Five different health statuses were defined using five-level EuroQol fivedimensional questionnaire (EQ-5D-5 L) descriptions [24, 25], including three treatment settings and two end-oflife scenarios. More details will be discussed in the next section. All subjects were asked for their full consent to participate in the study and no financial incentives were offered. 
Table 1 Scenarios of questionnaire

\begin{tabular}{|c|c|c|c|c|c|c|}
\hline & Health state & No & & EQ-5D-5 L description & QALY gain & $\begin{array}{l}\text { Period } \\
\text { (months) }^{\mathrm{a}}\end{array}$ \\
\hline \multirow[t]{6}{*}{ Treatment scenario } & Mild & 1 & \multirow[t]{2}{*}{12,122} & \multirow{2}{*}{$\begin{array}{l}\text { I have no problems in walking about; I have slight problems } \\
\text { washing or dressing myself; I have no problems doing } \\
\text { my usual activities; I have slight pain or discomfort; I am } \\
\text { slightly anxious or depressed }\end{array}$} & 0.2 & 15 \\
\hline & Mild & 2 & & & 0.4 & 31 \\
\hline & Moderate & 3 & \multirow[t]{2}{*}{23,332} & \multirow{2}{*}{$\begin{array}{l}\text { I have slight problems in walking about; I have moderate } \\
\text { problems washing or dressing myself; I have moderate } \\
\text { problems doing my usual activities; I have moderate pain } \\
\text { or discomfort; I am slightly anxious or depressed }\end{array}$} & 0.2 & 5 \\
\hline & Moderate & 4 & & & 0.4 & 10 \\
\hline & Severe & 5 & \multirow[t]{4}{*}{44,332} & \multirow{4}{*}{$\begin{array}{l}\text { I have severe problems in walking about; I have severe } \\
\text { problems washing or dressing myself; I have moderate } \\
\text { problems doing my usual activities; I have moderate pain } \\
\text { or discomfort; I am slightly anxious or depressed }\end{array}$} & 0.2 & 3 \\
\hline & Severe & 6 & & & 0.4 & 6 \\
\hline \multirow[t]{2}{*}{ Terminal illness } & & 7 & & & 0.2 & 15 \\
\hline & & 8 & & & 0.4 & 26 \\
\hline \multirow[t]{2}{*}{ Immediate death } & & 9 & \multirow[t]{2}{*}{11,115} & \multirow{2}{*}{$\begin{array}{l}\text { I have no problems in walking about; I have no problems } \\
\text { washing or dressing myself; I have no problems doing } \\
\text { my usual activities; I have no pain or discomfort; I am } \\
\text { extremely anxious or depressed }\end{array}$} & 0.2 & 3 \\
\hline & & 10 & & & 0.4 & 6 \\
\hline
\end{tabular}

a Since $\mathrm{QALY}=$ the period of life length (year) * utility of health state, the period was calculated as follows

For treatment scenarios, the period (month) $=\mathrm{QALY}$ gain/(utility of health state after treatment - utility of health state before treatment) $* 12$

Health state after treatment is perfect health, hence, the period (month) =QALY gain/ ( 1 - utility of health state before treatment) * 12

For terminal illness and immediate death, the treatment can prolong life expectancy in assumed health state, which should result in 0.2 or 0.4 QALY gain. Hence, for terminal illness the period (month) $=\mathrm{QALY}$ gain/utility of health state $* 12+3$. For immediate death, QALY gain/utility of health state $* 12$

\section{Questionnaire}

All together, we adopted 20 different questionnaires including 10 scenarios of each WTP technique. Each questionnaire contained 22 questions concerning quality of life, WTP, and demographic items as well as healthrelated issues. All questionnaires are identical except the part related to WTP. The demographic section included questions about age, sex, marital status, education, and family income. First, we evaluated the individuals' present health state using the EQ-5D-5 L. Part 2 consisted of a hypothetical health state and a WTP exercise in which we asked individuals to state the maximum amount he or she would be willing to pay for treatment of a hypothetical condition. An example of part 2 can be found in the Additional file 1 [see Additional file 1]. To avert possible extreme WTP values and reveal general treatment in each scenario, small QALY gains, 0.2 QALY and 0.4 QALY, were applied in this research. Altogether, 10 eliciting scenarios were constructed (see Table 1).

For treatment scenarios, a hypothetical scenario with description of EQ-5D-5 L (the health states mentioned in Table 1) was explained to participants. Without any treatment, they would live with the described health state for XX months. After XX months, they would fully recover. For each hypothetical health state, the WTP value was measured by the respondents' willingness to purchase the treatment.
We also specified the following conditions to each respondent to clarify the assumed situation; (a) the treatment was not reimbursed by public health insurance, the full amount had to be paid beforehand; (b) loss of income due to the illness need not be considered (it is compensated by social security.); and (c) payment for the treatment will influence the respondents' household.

"Terminal illness scenario" reflected the assumption that participants suffered a terminal disease with 3 months in severe health state (EQ-5D-5 L description: 44,332). A newly developed treatment could prolong life expectancy by 12 months (0.2 QALY) or 23 months (0.4 QALY) in that severe health state. For "immediate death scenario", we assumed that because of fatal sickness, the respondents would die immediately. However, in this scenario we hypothesized that there was a treatment that could prolong life expectancy by 3 months (0.2 QALY) or 6 months (0.4 QALY) in health state 11,115 . $^{1}$

The WTP payment was defined as the amount of outof-pocket expense to purchase an assumed intervention. Participants were asked if he or she would pay for the treatment. Those who replied "No" were then asked to give their reasons. If the answer was "yes", the participant

\footnotetext{
1 We used perfect health $(11,111)$ in the pilot study, which was believed to be too ideal since most people feel extreme anxious in face of death. Hence, 11,115 (5 means extreme anxious or depressed) was used for the immediate death scenario.
} 
was requested to provide the maximum amount they were willing to pay out of pocket. The PC had the following categories: $3200 \mathrm{RMB}$ (5\% of Chinese GDP per capita, USD 457), 6450 RMB (10\% of Chinese GDP per capita, USD 922), 12,900 RMB (20\% of Chinese GDP per capita, USD 1,844), 25,800 RMB (40\% of Chinese GDP per capita, USD 3,688), 51,600 RMB (80\% of Chinese GDP per capita, USD 7,376), 77,400 RMB (120\% of Chinese GDP per capita, USD 11,064), 103,200 RMB (160\% of Chinese GDP per capita, USD 14,753). We sent the payment card to respondents before the survey started, and those who agreed to pay for the assumed intervention were asked to choose their maximum WTP from the payment card.

\section{Data analysis}

Previous studies have applied two different methods of converting the data on WTP and QALY gains into WTP per QALY estimates, namely aggregated method and disaggregated method. The aggregated approach calculates the ratio by dividing the mean of WTP by the mean of QALY, whereas the disaggregated method estimates WTP/QALY for individuals, and subsequently estimates the mean value of WTP/QALY, which was proved to be a more appropriate method as it takes account of heterogeneity in preferences as well as individual's marginal rate of substitution between health and money [26, 27]. Hence, the disaggregated method was applied in this research.

Descriptive statistics (mean, SD, median, inter-quartile range, minimum, maximum) for the WTP values of the $\mathrm{PC}$ and the OE formats were computed. Zero response of each format were compared and excluded for further analysis. We compared the mean and the median WTP/ QALY obtained from the two elicitation methods of diverse scenarios using a two-sample equality test with bootstrapping.

Generalized linear models (GLMs) were carried out to control observed heterogeneity and test theoretical validity. In a broad sense, the theoretical validity of WTP/QALY estimates refers to whether the estimates concur with the underlying theory. The subsequent variables $^{2}$ were selected for regression analysis in conformity with previous research [11-13]: age, income, hypothetical health state, and QALY gain. Age was proven to be a significant factor of WTP/QALY in previous research [11], indicating that being younger led to a higher WTP/ QALY. Income is positively associated with WTP/QALY [12] and thus should be captured in the regression

\footnotetext{
2 The regressors were chosen based on the bivariate analysis (the MannWhitney U-tests for dichotomous variables, Kruskal-Wallis $\mathrm{H}$ tests for polychromous variables, Spearman's rank correlation coefficient for the continuous variable) as well as previous researches.
}

analysis. Furthermore, we also assumed that worse health state scenario [13] and smaller QALY gain should lead to a higher WTP/QALY [9]. For the base-case analysis, we included only positive WTP. For the further understanding of the difference of these two formats, we included all WTP responses, where zero WTP/QALY was converted into $1 \mathrm{RMB}$. In order to reduce the impact of outliers, the top $1 \%$ of values in both the $\mathrm{OE}$ and $\mathrm{PC}$ formats were trimmed for sensitive analysis. Moreover, we deleted all 18 samples which agreed to pay for intervention but did not give exact answers. Categorical variables were coded with dummy variables. We estimated GLMs with a loglink relationship. In order to choose an appropriate variance function for the GLMs, we performed modified Park test, which indicated gamma distribution. As for log link, this has the advantage of focusing on differences between groups of participants with respect to arithmetic rather than geometric means. Statistical analysis was performed with IBM SPSS version 23.0. and stata version 14.0.

\section{Results \\ Respondent characteristics and summary statistics}

Table 2 displays the demographic characteristics of respondents. In total, 461 individuals were involved, among whom 235 (51\%) answered the PC question, while 226 (49\%) answered the OE question. 61\% of participants had a college degree. Around 35\% of respondents had income less than 3000 RMB per month. Almost $19 \%$ participants in this research proclaimed that they were having some health problems. However, for all the dimensions in EQ-5D-5 L, most respondents reported no problem. The mean utility score of respondents was 0.95 . A small portion of respondents (5\%) had experienced hospitalization during the year. We found no significant differences between elicitation methods for all variables except education $(\mathrm{p}=0.001)$.

\section{Comparing formats with unconditional analysis}

The distribution of WTP/Q of the PC and the OE formats is displayed in Fig. 1. Furthermore, Table 3 presents descriptive statistics of WTP/QALY for the two elicitation methods. This research showed a small number of zero response, which is $12(5.1 \%)$ for the PC, 34 (15.0\%) for the OE. Detailed information about zero response can be found at Table 3. The range of median values for PC format for different questionnaires is 8000 to 258,000 RMB, whereas for OE is 7500 to 500,000 RMB. Figure 2 displays the ratio of accepted bids according to the elicitation method. These two crossing lines indicated that the $\mathrm{OE}$ format tended to elicit more extreme values, though the difference between two elicitation methods did not seem to be substantial.The results of equality tests of mean and median were presented in Table 4, 
Table 2 Respondents' characteristics $(N=461)$

\begin{tabular}{|c|c|c|c|}
\hline Characteristic & $\begin{array}{l}\text { Full sample } \\
\text { Mean } \pm \text { SD or } \mathrm{N}(\%)\end{array}$ & $\begin{array}{l}\text { PC } \\
\text { Mean } \pm \text { SD or } \mathrm{N}(\%)\end{array}$ & $\begin{array}{l}\text { OE } \\
\text { Mean } \pm \text { SD or } N(\%)\end{array}$ \\
\hline n & $461(100 \%)$ & 235 (51\%) & 226 (49\%) \\
\hline Age & $32.86 \pm 11.84$ & $31.92 \pm 11.27$ & $33.84 \pm 12.36$ \\
\hline \multicolumn{4}{|l|}{ Gender } \\
\hline Male & $219(48 \%)$ & $110(47 \%)$ & 109 (48\%) \\
\hline Female & $242(52 \%)$ & $157(53 \%)$ & $117(52 \%)$ \\
\hline \multicolumn{4}{|l|}{ Education $^{a}$} \\
\hline$\leq$ Primary school & $29(6 \%)$ & $11(5 \%)$ & $18(8 \%)$ \\
\hline Secondary school & $76(17 \%)$ & $25(11 \%)$ & $51(23 \%)$ \\
\hline High school & $76(17 \%)$ & $39(17 \%)$ & $37(16 \%)$ \\
\hline$\geq$ College & $280(61 \%)$ & $160(67 \%)$ & $120(53 \%)$ \\
\hline \multicolumn{4}{|l|}{ Marital status } \\
\hline Single & $223(48 \%)$ & $105(45 \%)$ & $118(52 \%)$ \\
\hline Married & $235(51 \%)$ & $130(56 \%)$ & $105(47 \%)$ \\
\hline Divorced/separated & $2(0 \%)$ & $0(0 \%)$ & $2(1 \%)$ \\
\hline Widowed & $1(0 \%)$ & $0(0 \%)$ & $1(0 \%)$ \\
\hline \multicolumn{4}{|l|}{ Income } \\
\hline$\leq 3000$ & $162(35 \%)$ & $83(35 \%)$ & $79(35 \%)$ \\
\hline $3001-5000$ & $173(38 \%)$ & $85(36 \%)$ & $88(39 \%)$ \\
\hline$>5000$ & $126(27 \%)$ & 67 (29\%) & $59(26 \%)$ \\
\hline Health utility & $0.95 \pm 0.07$ & $0.95 \pm 0.06$ & $0.94 \pm 0.09$ \\
\hline \multicolumn{4}{|c|}{ Hospitalization experience during the year } \\
\hline Yes & $20(5 \%)$ & $7(3 \%)$ & $14(6 \%)$ \\
\hline No & $441(95 \%)$ & $228(97 \%)$ & $213(94 \%)$ \\
\hline \multicolumn{4}{|l|}{ Health problems } \\
\hline Yes & $86(19 \%)$ & $44(19 \%)$ & $42(19 \%)$ \\
\hline No & $375(81 \%)$ & $191(81 \%)$ & $184(81 \%)$ \\
\hline
\end{tabular}

andicates there is significant difference between PC group and OE group on education

which were, to some degree, consistent with the figure of the ratio of accepted bids. The general tendency was that for mild health state scenario, the PC yielded higher mean value, whereas for all other four health scenarios, the OE method was witnessed with much bigger mean WTP/QALY valued except terminal illness scenario with 0.4 QALY gain. Equality test of mean with bootstrap indicated insignificant difference of the means of these two techniques for all types of questionnaires. No differences were found in the median for these two formats in all five scenarios

\section{Comparing formats with conditional analysis Separate estimations by elicitation format}

For each elicitation method we looked for the determinants of WTP/QALY with GLMs (Table 5). For both OE and $P C$ format, most variables were found to have significant effect on the value of WTP/QALY. The monetary value of QALY was proved to be significantly influenced by valuation scenarios in both models, while participants were prepared to pay more for more serious conditions, even though the difference of WTP/QALY values for terminal illness and base-case group (immediate death) was not significant in both formats. Furthermore, we confirmed that for both formats, smaller QALY gain led to a higher WTP/QALY. We found a positive effect of income on WTP/QALY for both formats-which argues for the validity of the stated-preference survey [24]. Age was assumed to be negatively related to participants' WTP: as respondents' age increase, their WTP/QALY decreased. However, for the PC technique, participants' age was not a statistically significant variable, whereas for the $\mathrm{OE}$ format, age was a statistically significant factor. The sensitivity analysis proved the robustness of these findings, which can be found in the Additional file 2 .

\section{Joint estimation over the two elicitation formats}

We studied the impact of the elicitation technique on WTP over the whole sample by introducing dummy variables for the $\mathrm{OE}$ format (the PC format as the reference). 


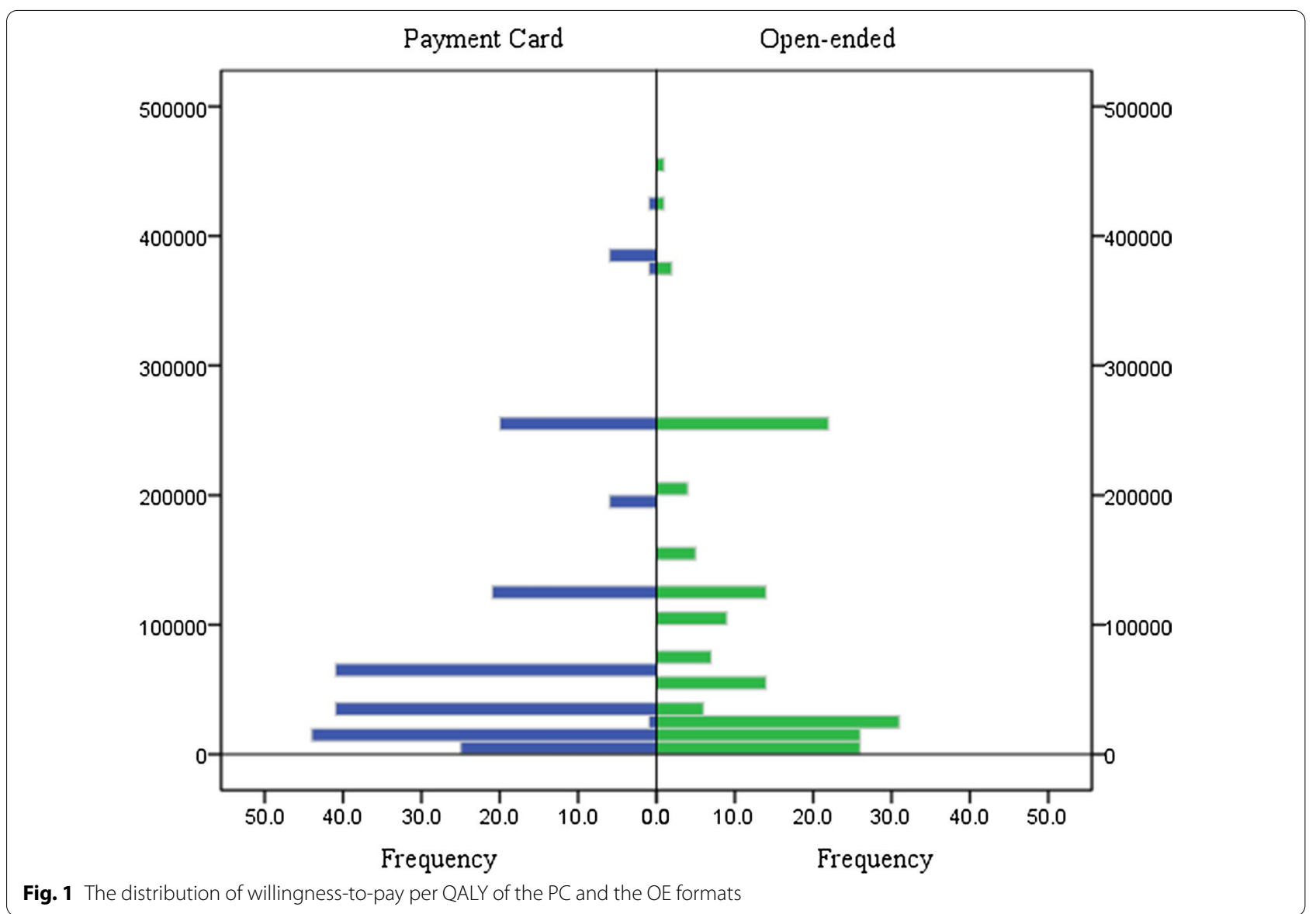

Fig. 1 The distribution of willingness-to-pay per QALY of the PC and the OE formats

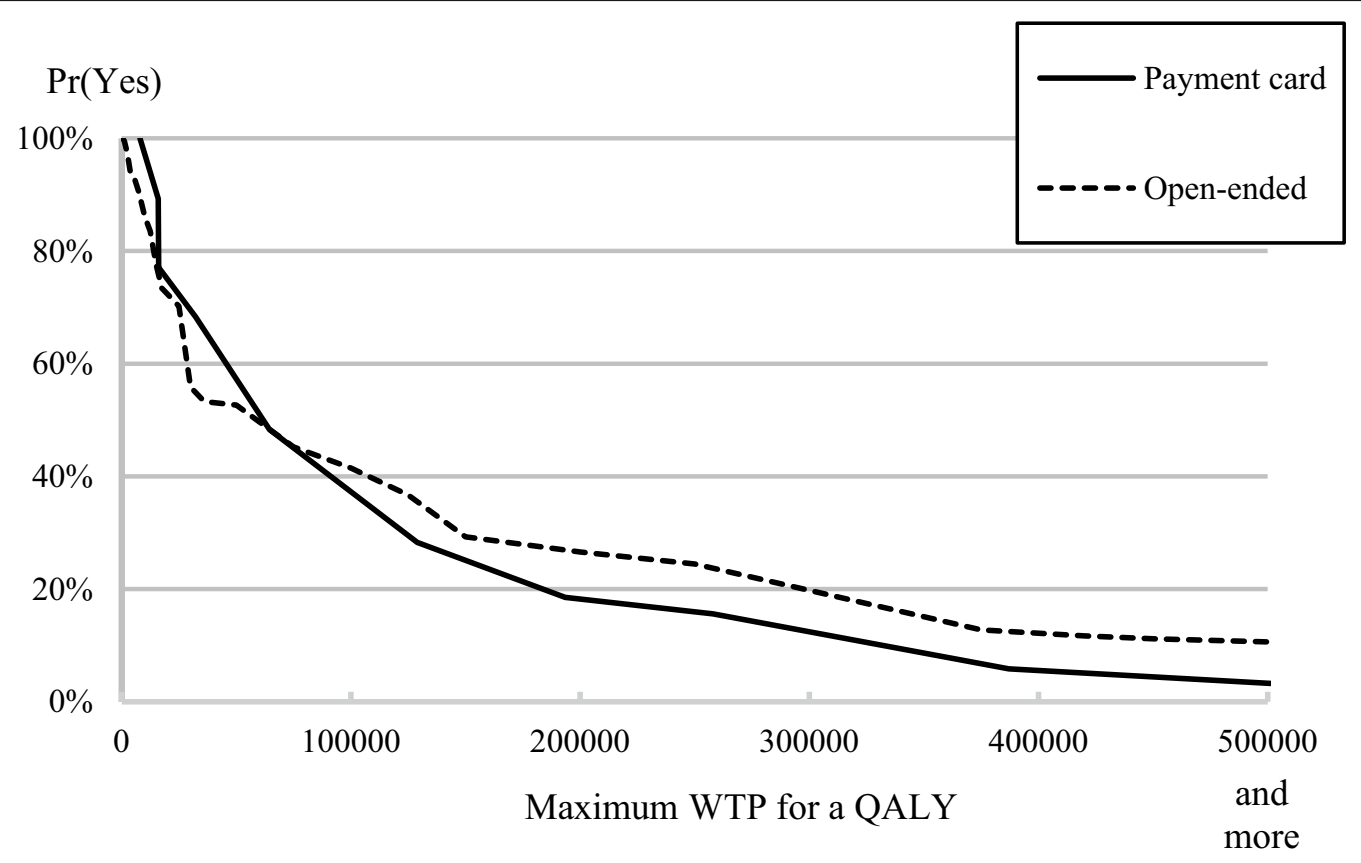

Fig. 2 Proportion of accepted bids by elicitation format 
Table 3 Descriptive statistics and equality tests of WTP per QALY using PC and OE formats

\begin{tabular}{|c|c|c|c|c|c|c|c|c|}
\hline Questionnaires & $\begin{array}{l}\text { WTP } \\
\text { technique }\end{array}$ & $N$ & $\begin{array}{l}\text { Zero } \\
\text { response, N } \\
(\%)\end{array}$ & Mean & Standard deviation & Median & Minimum & Maximum \\
\hline \multirow[t]{2}{*}{ Mild, 0.2 QALY } & PC & 26 & $1(3.8 \%)$ & 37,890 & 32,658 & 28,426 & 500 & 129,000 \\
\hline & OE & 25 & $4(16 \%)$ & 25,476 & 20,243 & 23,000 & 5000 & 100,000 \\
\hline \multirow[t]{2}{*}{ Mild, 0.4 QALY } & PC & 25 & $0(0 \%)$ & 21,595 & 12,914 & 16,125 & 8000 & 64,500 \\
\hline & OE & 25 & $4(16 \%)$ & 18,119 & 27,211 & 7500 & 500 & 125,000 \\
\hline \multirow[t]{2}{*}{ Moderate, 0.2 QALY } & PC & 21 & $0(0 \%)$ & 75,631 & 107,888 & 64,500 & 16,000 & 516,000 \\
\hline & OE & 21 & $2(10 \%)$ & 105,447 & 125,083 & 100,000 & 2500 & 516,000 \\
\hline \multirow[t]{2}{*}{ Moderate, 0.4 QALY } & PC & 23 & $1(4.3 \%)$ & 51,295 & 54,553 & 32,250 & 8000 & 258,000 \\
\hline & OE & 22 & $3(13.6 \%)$ & 84,934 & 83,739 & 75,000 & 1250 & 250,000 \\
\hline \multirow[t]{2}{*}{ Severe, 0.2 QALY } & PC & 22 & $0(0 \%)$ & 34,409 & 18,187 & 32,250 & 16,000 & 64,500 \\
\hline & OE & 19 & $2(11 \%)$ & 40,000 & 36,827 & 25,000 & 10,000 & 150,000 \\
\hline \multirow[t]{2}{*}{ Severe, 0.4 QALY } & PC & 23 & $5(21.7 \%)$ & 13,278 & 9666 & 8000 & 750 & 32,250 \\
\hline & OE & 20 & $1(5 \%)$ & 19,868 & 20,331 & 12,500 & 1250 & 75,000 \\
\hline \multirow[t]{2}{*}{ Terminal illness, 0.2 QALY } & PC & 25 & $1(4 \%)$ & 280,177 & 219,279 & 258,000 & 16,000 & $1,000,000$ \\
\hline & OE & 18 & $11(61 \%)$ & 570,714 & 413,727 & 420,000 & 75,000 & $1,000,000$ \\
\hline \multirow[t]{2}{*}{ Terminal illness, 0.4 QALY } & PC & 26 & $1(4 \%)$ & 232,600 & 120,808 & 258,000 & 64,500 & 516,000 \\
\hline & $\mathrm{OE}$ & 25 & $0(0 \%)$ & 221,000 & 127,614 & 200,000 & 25,000 & 500,000 \\
\hline \multirow[t]{2}{*}{ Immediate death, 0.2 QALY } & PC & 19 & $2(11 \%)$ & 273,647 & 237,721 & 129,000 & 16,000 & 750,000 \\
\hline & $\mathrm{OE}$ & 26 & $3(12 \%)$ & 620,913 & $1,019,954$ & 500,000 & 15,000 & $5,000,000$ \\
\hline \multirow[t]{2}{*}{ Immediate death, 0.4 QALY } & PC & 25 & $1(4 \%)$ & 189,984 & 286,863 & 64,500 & 8000 & $1,250,000$ \\
\hline & OE & 25 & $4(16 \%)$ & 242,381 & 235,387 & 250,000 & 7500 & 750,000 \\
\hline
\end{tabular}

PC payment card, $O E$ open-ended

Table 4 Comparison between the PC and the OE formats by different scenarios

\begin{tabular}{|c|c|c|c|c|}
\hline Questionnaires & Mean Difference & $\begin{array}{l}95 \% \text { Interval of mean difference } \\
\text { by bootstrap }\end{array}$ & $\begin{array}{l}\text { Equality test of mean } \\
\text { (bootstrap) }\end{array}$ & $\begin{array}{l}\text { Equality test } \\
\text { of median }\end{array}$ \\
\hline Mild, 0.2 QALY & 12,413 & $(-2621,27,294)$ & 0.141 & 0.067 \\
\hline Mild, 0.4 QALY & 3476 & $(-10,464,14,469)$ & 0.598 & 0.903 \\
\hline Moderate, 0.2 QALY & $-29,816$ & $(-108,607,41,299)$ & 0.477 & 0.595 \\
\hline Moderate, 0.4 QALY & $-33,639$ & $(-82,653,9596)$ & 0.165 & 0.662 \\
\hline Severe, 0.2 QALY & -5590 & $(-25,971,12,205)$ & 0.596 & 0.917 \\
\hline Severe, 0.4 QALY & -6591 & $(-17,302,2750)$ & 0.22 & 0.408 \\
\hline Terminal illness, 0.2 QALY & $-290,537$ & $(-638,371,28,961)$ & 0.113 & 0.623 \\
\hline Terminal illness, 0.4 QALY & 11,600 & $(-58,726,78,265)$ & 0.728 & 0.777 \\
\hline Immediate death, 0.2 QALY & $-347,266$ & $(-865,403,-3927)$ & 0.28 & 0.522 \\
\hline Immediate death, 0.4 QALY & $-52,396$ & $(-200,299,104,131)$ & 0.51 & 0.309 \\
\hline
\end{tabular}

The GLM with whole sample including only positive WTP indicated statistically significant positive effect on the $\mathrm{OE}$ results, demonstrating that $\mathrm{OE}$ format has higher chance to elicit higher WTP/QALY than the PC format. Nevertheless, when we converted all zero WTP/Q into 1 $\mathrm{RMB}$, the difference between these two formats became insignificant. We may conclude that the imbalanced zero response distribution cause the main difference of these two formats. Regarding the determinants of WTP, the joint estimation confirms previous results: a significant and negative effect of age and QALY gain, a significant and positive effect of income. WTP/QALY was also proved to be affected by valuation scenarios.

\section{Discussion}

We compared WTP/QALY estimates generated from the $\mathrm{PC}$ format and the OE format and found that the mean WTP values of these two formats varied dramatically for different scenarios and QALY gains. The OE format tended to elicit more extreme values, indicating that for 
Table 5 Generalized linear models for WTP/QALY values

\begin{tabular}{|c|c|c|c|c|c|c|c|c|c|c|c|c|}
\hline & \multicolumn{3}{|c|}{ All, $n=415$} & \multicolumn{3}{|c|}{ ALL, including zero WTP } & \multicolumn{3}{|c|}{$\mathrm{PC}, \mathrm{n}=223$} & \multicolumn{3}{|c|}{$\mathrm{OE}, \mathrm{n}=192$} \\
\hline & Coef. & Std. Err. & $P>z$ & Coef. & Std. Err. & $P>z$ & Coef. & Std. Err. & $P>z$ & Coef. & Std. Err. & $P>z$ \\
\hline OE (vs. PC) & 0.21 & 0.10 & $0.03^{*}$ & 0.09 & 0.1 & 0.38 & & & & & & \\
\hline \multicolumn{13}{|c|}{ Scenario (vs. Immediate death) } \\
\hline Mild & -2.44 & 0.15 & $0.00^{* *}$ & -2.45 & 0.16 & $0.00^{* *}$ & -2.16 & 0.19 & $0.00^{* *}$ & -2.80 & 0.22 & $0.00^{* *}$ \\
\hline Moderate & -1.39 & 0.15 & $0.00^{* *}$ & -1.35 & 0.16 & $0.00^{* *}$ & -1.52 & 0.20 & $0.00^{* *}$ & -1.24 & 0.23 & $0.00^{* *}$ \\
\hline Severe & -2.35 & 0.15 & $0.00^{* *}$ & -2.33 & 0.16 & $0.00^{* *}$ & -2.27 & 0.20 & $0.00^{* *}$ & -2.42 & 0.23 & $0.00^{* *}$ \\
\hline Terminal illness & 0.00 & 0.15 & 0.99 & -0.07 & 0.16 & 0.66 & 0.06 & 0.19 & 0.76 & -0.10 & 0.23 & 0.66 \\
\hline \multicolumn{13}{|c|}{ QALY gain (vs. 0.2 QALY) } \\
\hline 0.4 QALY & -0.61 & 0.10 & $0.00^{* *}$ & -0.57 & 0.1 & $0.00^{* *}$ & -0.48 & 0.12 & $0.00^{* *}$ & -0.72 & 0.15 & $0.00^{* *}$ \\
\hline \multicolumn{13}{|l|}{ Income (vs. $\leq 3000$ ) } \\
\hline $3001-5000$ & 0.21 & 0.11 & 0.06 & 0.23 & 0.12 & 0.06 & 0.16 & 0.14 & 0.27 & 0.21 & 0.18 & 0.24 \\
\hline$>5000$ & 0.68 & 0.12 & $0.00^{* *}$ & 0.69 & 0.13 & $0.00^{* *}$ & 0.61 & 0.16 & $0.00^{* *}$ & 0.76 & 0.20 & $0.00^{* *}$ \\
\hline \multicolumn{13}{|l|}{ Age (vs. $<25)$} \\
\hline 25-39 & -0.14 & 0.12 & 0.24 & -0.11 & 0.12 & 0.38 & 0.10 & 0.15 & 0.51 & -0.42 & 0.18 & $0.02^{*}$ \\
\hline$\geq 40$ & -0.36 & 0.12 & $0.00^{* *}$ & -0.39 & 0.12 & $0.00^{* *}$ & -0.25 & 0.15 & 0.11 & -0.49 & 0.18 & $0.01^{*}$ \\
\hline Constant & 12.63 & 0.16 & $0.00^{* *}$ & 12.55 & 0.17 & $0.00^{* *}$ & 12.41 & 0.18 & $0.00^{* *}$ & 13.05 & 0.25 & $0.00^{* *}$ \\
\hline
\end{tabular}

$P C$ payment card, $O E$ open-ended, $Q A L Y$ quality-adjusted life year

${ }^{*}$ Indicates that there are statistically significant differences at the $5 \%$ level; ${ }^{* *}$ indicates that there are statistically significant differences at the $1 \%$ level

mild health state scenario, the PC yielded higher mean value, whereas for all other four health scenarios, the $\mathrm{OE}$ method was witnessed with much bigger mean WTP/ QALY. However, equality test of mean and median demonstrated insignificant difference of these two formats for all scenarios. GLM regression demonstrated the validity of both and statistically significant positive effect on the OE results. Further analysis indicated that the imbalanced zero response distribution caused the main difference of these two formats.

The theoretical validity can be examined by determining whether the results are consistent with theoretical constructs. Probing the theoretical validity is the most popular test of validity applied to stated-preference techniques mostly since it is comparatively easy to perform. The performance of both PC and OE format appears to be highly satisfactory, whereas the PC format failed to comply with the assumption that being younger leads to a higher WTP/QALY. In comparison with the PC format, the $\mathrm{OE}$ technique had a stronger association with most variables in the regression model. In theory, the PC question tends to cause range bias. In the OE form, only after a careful reflection can respondents answer WTP question [18], which might be a fundamental procedure in assessing the value of health.

We did not pool all the data and present overall mean WTP/QALY estimates for each format because of the variation of mean WTP/QALY for different scenarios with different QALY gain. Instead, detailed information of descriptive statistics of different types of questionnaires were reported for each format. It was found that the OE format was related with lower WTP/ QALY for less serious condition and higher values for more serious condition. Moreover, the results of GLM regressions demonstrated that the $\mathrm{OE}$ format tended to higher WTP/QALY, which is inconsistent from previous research in healthcare. By asking questions of women's WTP for a screen process, Donaldson et al. [20] concluded that the PC format was related with higher mean and median WTP, which was proved again by the study on colorectal cancer screening of Whynes and colleagues [21]. We may argue here that body screening as well as mild treatment scenario in this research could be considered as less serious condition, where the OE format tended to elicit lower values.

This is the first study to compare WTP/QALY estimates generated from the $\mathrm{PC}$ and the $\mathrm{OE}$ formats. However, we have encountered certain practical limitations. First, only the theoretical validity of the two eliciting methods was performed; essential elements like external validity and reliability were not assessed in this study. Second, quota sampling instead of probability sampling was applied in this research. Hence, the participants used in this study may not be a perfect representation of the Chinese population. Due to the cognitive challenge of this type of survey, most studies of WTP include a sample with a higher education compared to the general population [28, 29]. In this study, those with higher levels of education were over-represented. However, we found that education level had no 
significant impact on WTP/QALY. Hence, the potential bias in the WTP estimate is likely to be minor. Third, according to previous research [4], respondents' health state, especially those who had health state worse than the hypothetical questions, might influence their WTP for a QALY, but we did not perform any analysis regarding to this issue since most participants stated perfect health. There were 5 participants whose health state is worse than the illness state in the hypothetical questions, all came from mild treatment scenario (two for PC group and three for OE group). One refused to pay anything for the treatment, the other four state plausible payment. Moreover, we did not distinguish genuine zeros from protest responses, which might potentially bias our conclusion. Finally, a critical limitation is the imaginary nature of all WTP surveys [30]. Like other studies, the participants might find it hard to picture a hypothetical health state that significantly differs from conditions that they have experienced before. More research about the validity of various WTP eliciting methods would be needed for a robust estimation of monetary value per QALY.

\section{Conclusions}

The study compared WTP/QALY estimates generated from the $\mathrm{PC}$ and the $\mathrm{OE}$ formats and found that the OE format tended to elicit lower values for less serious condition and higher values for more serious condition. However, equality test of mean and median demonstrated insignificant difference of these two formats for all scenarios. GLM regression demonstrated the validity of both and statistically significant positive effect on the OE results. More research about the validity of various WTP eliciting methods would be needed for a robust estimation of WTP/QALY.

\section{Abbreviations \\ PC: Payment card; OE: Open-ended; WTP:Willingness-to-pay; QALY: Quality- adjusted life year; ICER: Incremental cost-effectiveness ratio; CEA: Cost-effectiveness analysis; CV: Contingent valuation; EQ-5D-5L: Five-level EuroQol five-dimensional questionnaire.}

\section{Supplementary Information}

The online version contains supplementary material available at https://doi. org/10.1186/s12962-021-00298-0.

Additional file 1. An example of willing-to-pay question. This is an example of part 2 of the questionnaire, which contains a hypothetical health state and a WTP exercise. Individuals was asked to state the maximum amount he or she would be willing to pay for treatment for a hypothetical condition.

Additional file 2. Sensitive analysis of generalized linear models for WTP/ QALY values. This is the result of sensitive analysis of GLMs.
Acknowledgements

The authors would like to thank all respondents for their participation in this research.

\section{Authors' contributions}

$Z Y$ and LS conceived the original concept of the study, applied for the grant and assisted in study protocol development and implementation. ZY, FL, JM, $\mathrm{ZZ}$ and CW conducted this survey and wrote the manuscript. All authors contributed to the final design of the study protocol. All authors read and approved the final manuscript.

\section{Funding}

This work was supported by the Research Project of Liaoning Province Education Department (2019), China (Grant No. 2019WZD01). The funders of the study had no role in study design, data collection, data analysis, data interpretation, writing of the manuscript, or publication of this article.

\section{Availability of data and materials}

The datasets used during the current study are available from the corresponding author on reasonable request.

\section{Declarations}

\section{Ethics approval and consent to participate}

According to Ethical review methods for human biomedical research issued by Ministry of Health in China, scientific research department of Shenyang Pharmaceutical University, who is responsible for the ethics review, ruled that no formal ethics approval was required in this case. Considering the survey was carried out via telephone, written consent was not available. Instead, verbal informed consent was obtained from the respondents for the publication of this report.

\section{Consent for publication}

Not applicable.

\section{Competing interests}

The author declares that he has no competing interests.

Received: 8 June 2020 Accepted: 7 July 2021

Published online: 19 July 2021

\section{References}

1. Baker R, Chilton S, Donaldson C, et al. Searchers vs surveyors in estimating the monetary value of a QALY: resolving a nasty dilemma for NICE. Health Econ Pol Law. 2011;6:435.

2. Vallejo-Torres L, García-Lorenzo B, Castilla I, et al. On the estimation of the cost-effectiveness threshold: why, what, how? Value Health. 2016;19(5):558-66.

3. Woods B, Revill P, Sculpher M, et al. Country-level cost-effectiveness thresholds: initial estimates and the need for further research. Value Health. 2016;19(8):929-35.

4. Gyrd-Hansen D. Willingness to pay for a QALY. Pharmacoeconomics. 2005;23(5):423-32.

5. Carson, Richard, T. Contingent valuation: a user's guide. Environ Sci Technol. 2000;34(8):1413-18.

6. Robinson A, Gyrd-Hansen D, Bacon P, Baker R, Pennington M, Donaldson C, Team E. Estimating a WTP-based value of a QALY: the 'chained'approach. Soc Sci Med. 2013 Sep;1:92:92-104.

7. Bobinac A, Van Exel NJA, Rutten FFH, et al. Willingness to pay for a quality-adjusted life-year: the individual perspective. Value Health 2010;13(8):1046-55.

8. Bobinac A, van Exel J, Rutten FFH, et al. The value of a QALY: individual willingness to pay for health gains under risk. Pharmacoeconomics. 2014;32(1):75-86.

9. Bobinac A, van Exel NJA, Rutten FFH, et al. GET MORE, PAY MORE? An elaborate test of construct validity of willingness to pay per QALY estimates obtained through contingent valuation. J Health Econ. 2012;31(1):158-68 
10. Nimdet K, Ngorsuraches S. Willingness to pay per quality-adjusted life year for life-saving treatments in Thailand. BMJ Open. 2015;5:10.

11. Martín-Fernández J, Polentinos-Castro E, del Cura-González MI, ArizaCardiel G, Abraira V, Gil-LaCruz Al, García-Pérez S. Willingness to pay for a quality-adjusted life year: an evaluation of attitudes towards risk and preferences. BMC Health Serv Res. 2014 Dec;14(1):287.

12. Lieu TA, Ray GT, Ortega-Sanchez IR, Kleinman K, Rusinak D. Willingness to pay for a QALY based on community member and patient preferences for temporary health states associated with herpes zoster. Pharmacoeconomics. 2009;27(12):1005-16.

13. Shiroiwa T, Igarashi A, Fukuda T, Ikeda S. WTP for a QALY and health states: more money for severer health states? Cost Effect Resour Allocat. 2013;1(1):22.

14. Ryen $L$, Svensson M. The willingness to pay for a quality adjusted life year: a review of the empirical literature. Health Econ. 2015;24(10):1289-301.

15. Smith RD. The discrete-choice willingness-to-pay question format in health economics: should we adopt environmental guidelines? Med Decis Making. 2000 Apr;20(2):194-204.

16. Mitchell RC, Carson RT. An experiment in determining willingness to to pay for national water quality improvements. Washington: Resources for the Future; 1981.

17. Jones-Lee MW. The economics of safety and physical risk. Berlin: Basil Blackwell; 1989

18. Reja U, Manfreda KL, Hlebec V, Vehovar V. Open-ended vs. close-ended questions in web questionnaires. Dev Appl Stat. 2003;19(1):159-77.

19. Riera P. Incentive compatibility in environmental valuation: some positive results. In EAERE 12th Annual Conference; 2003.

20. Donaldson C, Thomas R, Torgerson DJ. Validity of open-ended and payment scale approaches to eliciting willingness to pay. Appl Econ. 1997;29(1):79-84.
21. Whynes DK, Frew E, Wolstenholme JL. A comparison of two methods for eliciting contingent valuations of colorectal cancer screening. J Health Econ. 2003;22(4):555-74.

22. Lopez-Martin B, Montes C, Benayas J. Economic valuation of biodiversity conservation: the meaning of numbers. Conserv Biol. 2008;22(3):624-35.

23. Gyrd-Hansen D, Jensen ML, Kjaer T. Framing the willingness-to-pay question: impact on response patterns and mean willingness to pay. Health Econ. 2014 May;23(5):550-63.

24. Herdman M, Gudex C, Lloyd A, et al. Development and preliminary testing of the new five-level version of EQ-5D (EQ-5D-5L). Qual Life Res. 2011;20(10):1727-36.

25. Luo N, Liu G, Li M, et al. Estimating an EQ-5D-5L value set for China. Value Health. 2017;20(4):662-9.

26. Gyrd-Hansen D, Kjær T. Disentangling WTP per QALY data: different analytical approaches, different answers. Health economics. 2012 Mar;21(3):222-37.

27. Rashidian A, Rasekh H, Foroughi M, Olyaeemanesh A. Monetary value of quality-adjusted life years (QALY) among patients with cardiovascular disease: a willingness to pay study. Iran J Pharm Res. 2017;16(2):820-30.

28. Sund B, Svensson M. Estimating a constant WTP for a QALY - a mission impossible? Eur J Health Econ. 2018;19(6):871-80.

29. Olofsson S, Gerdtham UG, Hultkrantz L, et al. Value of a QALY and VSI estimated with the chained approach. Eur J Health Econ. 2019;20(7):1063-77.

30. Hanemann WM. The economic theory of WTP and WTA. Valuing Environ Prefer. 1999:8:42-96.

\section{Publisher's Note}

Springer Nature remains neutral with regard to jurisdictional claims in published maps and institutional affiliations.
Ready to submit your research? Choose BMC and benefit from:

- fast, convenient online submission

- thorough peer review by experienced researchers in your field

- rapid publication on acceptance

- support for research data, including large and complex data types

- gold Open Access which fosters wider collaboration and increased citations

- maximum visibility for your research: over $100 \mathrm{M}$ website views per year

At BMC, research is always in progress.

Learn more biomedcentral.com/submissions 